\title{
Dynamics of 45S rDNA sites in the cell cycle: fragile sites and chromosomal stability in Lolium and Festuca
}

L.C. Rocha ${ }^{1}$, G.A. Silva ${ }^{1}$, F.O. Bustamante ${ }^{1}$, R.A.D. Silveira ${ }^{1}$, A. Mittlemann ${ }^{2,3}$ and V.H. Techio ${ }^{1}$

${ }^{1}$ Universidade Federal de Lavras, Departamento de Biologia, Lavras, MG, Brasil ${ }^{2}$ Embrapa Gado de Leite, Juiz de Fora, MG, Brasil

${ }^{3}$ Embrapa Clima Temperado, Pelotas, RS, Brasil

Corresponding author: V.H. Techio

E-mail:vhtechio@gmail.com

Genet. Mol. Res. 16 (1): gmr16019156

Received September 5, 2016

Accepted November 17, 2016

Published January 23, 2017

DOI http://dx.doi.org/10.4238/gmr16019156

Copyright (C) 2017 The Authors. This is an open-access article distributed under the terms of the Creative Commons Attribution ShareAlike (CC BY-SA) 4.0 License.

\begin{abstract}
Analyses carried out with fluorescence in situ hybridization (FISH) in C-metaphases of the Lolium-Festuca complex have shown the occurrence of spontaneous fragile sites (FSs) in 45S rDNA regions. FSs are expressed as gaps but they do not result in breaks or chromosomal fragments in these species. These gaps have high DNA condensation observed as thin chromatin fibers that connect the apparent segments of the fragile chromosome, allowing for genomic stability. Assessing the behavior of these regions in the cell cycle of Lolium and Festuca species may lead to a better understanding of the dynamics that preserve stability during cell division. Furthermore, it is interesting to track the dynamics of chromosomes bearing 45S rDNA sites in the cell cycle as well as to observe the expression of FSs with no effect of the mitotic block. We observed variation in both the number and
\end{abstract}


size of 45S FISH signals from the S/G2 phases of interphase and from prophase to anaphase where gaps in $45 \mathrm{~S}$ rDNA sites also were observed. The change in the degree of condensation of the $45 \mathrm{~S}$ site begins in the $\mathrm{S} / \mathrm{G} 2$ phase and appears to be related to the transcriptional demand. Taking into account that the number of $45 \mathrm{~S}$ rDNA sites tends to be reestablished when cells reach telophase, we suggest that the chromatin fiber goes back to the normal condensation level to the anaphase (after segregation), allowing for the approximation of chromosome segments and ensuring dynamics that favor the genomic stability of these species.

Key words: Genetic stability; Chromosomal fragments; Fragile site; Gene activity-dependent decondensation; Chromatin fiber;

High decondensation;

\section{INTRODUCTION}

Fragile sites (FSs) are chromosome regions prone to breaks or narrowing with the subsequent formation of gaps with reduced coloration due to the lower degree of chromatin compaction in the chromosome or even due to chromosome breakages (Richards, 2001; Glover, 2006). In humans, FSs are well-studied and related to epigenetic modifications, as well as replicative and transcriptional stress (Wang, 2006; Leman and Noguchi, 2013).

In some plants, FSs are expressed in 45S rDNA sites (Huang et al., 2008, 2009, 2012; Waminal et al., 2013; Bustamante et al., 2014; Grabowska-Joachimiak et al., 2015; Rocha et al., 2015, 2016; Lan et al., 2016). In Lolium multiflorum Lam. and Lolium perenne L., FSs are randomly distributed in $45 \mathrm{~S}$ rDNA sites and promote changes in the number and position of fluorescence in situ hybridization (FISH) signals. The predominant number of described $45 \mathrm{~S}$ rDNA sites is six and seven for L. multiflorum and L. perenne, respectively (Thomas et al., 1996; Rocha et al., 2015). However, in C-metaphases with FSs, the number of 45S FISH signals range from 6 to 13 in L. multiflorum and from 7 to 13 in L. perenne. In intact chromosomes, invariably, the signals are located at interstitial chromosome positions, whereas in chromosomes with FSs, the variable-sized signals are located in the terminal regions. Initially, it was proposed that the occurrence of breakages or gaps in these regions resulted in the formation of chromosomal fragments (Huang et al., 2008; Bustamante et al., 2014; Rocha et al., 2015).

Recently, it was reported that FSs are also present in Festuca arundinacea and Festulolium hybrids (Rocha et al., 2016). In the same study, it was shown that FSs are not expressed through chromosomal breakages but rather as gaps covered by a thin DNA fiber, not detected by 4',6-diamidino-2-phenylindole (DAPI), connecting parts of the fragile chromosomes. The presence of these DNA fibers in FSs allows the maintenance of chromosomal integrity and an amount of nuclear DNA with a low percentage of micronuclei. This suggests that there is no loss of chromosome fragments in these genotypes. Rocha et al. (2016) suggested that the chromatin fiber in FSs of Lolium, Festuca, and Festulolium hybrids have a high decondensation process related to an increased genic activity, thus, supporting the findings by Huang et al. (2012), Bustamante et al. (2014), and Rocha et al. (2015).

So far, reports on FSs in Lolium and Festuca have been made based on metaphasic chromosomes under the effect of thermal shock $\left(0^{\circ} \mathrm{C}\right)$ used as a mitotic block. Observing the behavior of $45 \mathrm{~S}$ rDNA sites in the cell cycle may provide information on the spontaneous

Genetics and Molecular Research 16 (1): gmr16019156 
occurrence of FSs, thus, allowing for monitoring of the spatial/temporal expression patterns as well as observation of the dynamics that contribute to the genetic stability.

\section{MATERIAL AND METHODS}

The experiments were carried out with L. multiflorum (access No. LOL 161) and $L$. perenne ('Ellet'), both $2 \mathrm{n}=2 \mathrm{x}=14$ (Pereira et al., 2014; Rocha et al., 2015), in addition to two $F$. arundinacea cultivars ('Rizomat' and 'Quantum II') $2 \mathrm{n}=4 \mathrm{x}=42$. The Lolium species came from Banco Ativo de Germoplasma de Plantas Forrageiras (Active Germplasm Bank) and Embrapa Recursos Genéticos e Biotecnologia. Seeds from F. arundinacea cultivars were commercially obtained.

Roots were collected and fixed in Carnoy (3:1 ethanol:acetic acid) and stored at $-4^{\circ} \mathrm{C}$ for at least $24 \mathrm{~h}$. To prepare slides, roots were subjected to enzymatic maceration in pectinase/cellulose solution (2/4\%) (Sigma-Aldrich ${ }^{\mathrm{TM}}$, St Louise, MO, USA) for $130 \mathrm{~min}$ for L. multiflorum and $L$. perenne, and $105 \mathrm{~min}$ for $F$. arundinacea in an oven at $37^{\circ} \mathrm{C}$. Slides were then flame-dried (Dong et al., 2000). For FISH, a 45S rDNA probe (pTa 71 Triticum aestivum L.) marked with digoxigenin through a nick translation reaction was used. Slides were denatured in $70 \%$ formamide in SSC 2X for $1 \mathrm{~min}$ and $40 \mathrm{~s}$ at $85^{\circ} \mathrm{C}$ and then dehydrated in an alcohol series. The mixture containing the probe (50\% formamide SSC 2X, 10\% dextran sulfate, and approximately $50 \mathrm{ng}$ marked probes) was denatured at $95^{\circ} \mathrm{C}$ for $8 \mathrm{~min}$. The hybridization was conducted at $37^{\circ} \mathrm{C}$ in a moistened chamber for at least $16 \mathrm{~h}$. The detection was carried out with TRITC (tetramethylrhodamine) in TNB (sodium chloride-Tris buffer) for $1 \mathrm{~h}$ at $37^{\circ} \mathrm{C}$ in a moistened chamber. Slides were mounted on Vectashield with DAPI and evaluated on an epifluorescence microscope with 358/461 (DAPI) and 550/575 (TRITC) excitation/emission wavelengths. Images digitalized using a cooled monochrome camera AxioCamHRm (Zeiss, Oberkochen, Baden-Württemberg, Germany) were processed by using the Axio Vision Release 4.8.2 (Zeiss) software and Adobe Photoshop CS6.

\section{RESULTS}

In the three species evaluated, the $\mathrm{S} / \mathrm{G} 2$ interphase nuclei had the highest number of $45 \mathrm{~S}$ rDNA probe signals in comparison to the G1 nuclei (Figure 1). The size of the signals at interphase ranged from 0.3 to $0.8 \mu \mathrm{m}$ (Figures $2 \mathrm{~A}$ and $\mathrm{B}, 3 \mathrm{~A}$ and $\mathrm{B}, 4 \mathrm{~A}$ and $\mathrm{B}$, and $5 \mathrm{~A}$ and $\mathrm{B}$ ).
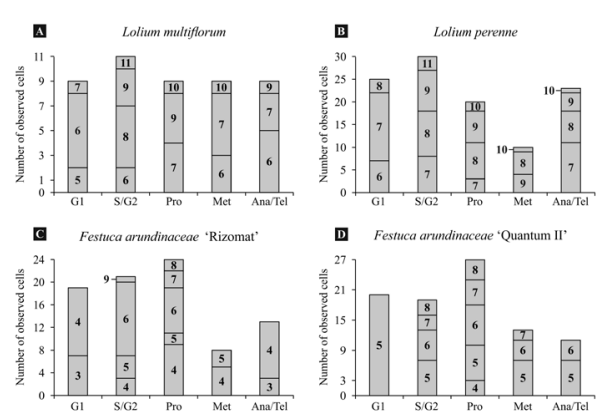

Figure 1. Number of cells analyzed in different phases of the cell cycle of Lolium multiflorum (A), Lolium perenne (B), Festuca arundinacea 'Rizomat' (C), and Festuca arundinacea 'Quantum II' (D). Within columns numbers represent the variability in number of $45 \mathrm{~S}$ rDNA signals found within each phase of the cell cycle. G1 and S/G2 represent subphases of interphase and the abbreviations correspond to prophase (Pro), metaphase (Met), and anaphase and telophase (Ana/Tel).

Genetics and Molecular Research 16 (1): gmr16019156 

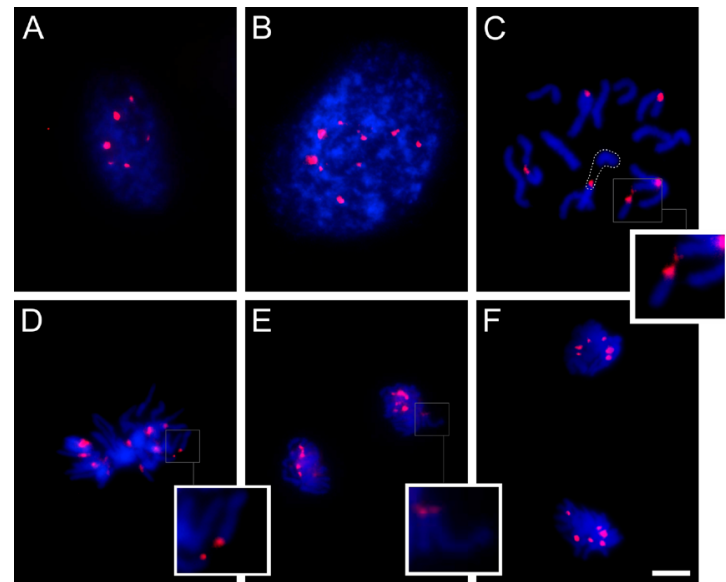

Figure 2. Cell cycle of Lolium multiflorum $(2 \mathrm{n}=2 \mathrm{x}=14)$, in red: $45 \mathrm{~S}$ rDNA signals. A. Interphase G1 with six 45S rDNA signals, B. Interphase S/G2 with eleven $45 \mathrm{~S}$ rDNA signals, C. Prometaphase: the dotted line is an FS in which the 45S rDNA signal is only found in one of the chromosome parts and the enlargement shows a gap in the 45S rDNA site, D. Metaphase: the enlargement shows 45S rDNA signals on both sides of the fragile chromosome, E. Late anaphase: the enlargement shows a gap in the $45 \mathrm{~S}$ rDNA site, F. Late anaphase with six $45 \mathrm{~S}$ rDNA signals on each pole. Scale bar: $5 \mu \mathrm{m}$.
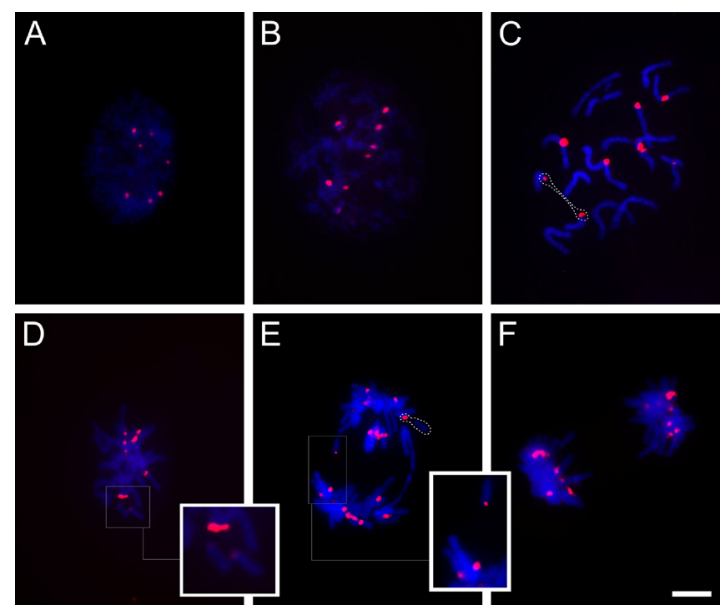

Figure 3. Cell cycle of Lolium perenne $(2 \mathrm{n}=2 \mathrm{x}=14)$, in red: $45 \mathrm{~S}$ rDNA signals. A. Interphase G1 with seven $45 \mathrm{~S}$ rDNA signals, B. Interphase S/G2 with nine 45S rDNA signals, C. Prometaphase: the dotted line shows 45S rDNA signals in both parts of the fragile chromosome, D. Metaphase: the enlargement shows two fragile chromosomes, E. Early anaphase: the dotted line shows the $45 \mathrm{~S}$ signal in only one of the fragile parts and the enlargement shows a fragile chromosome with distant segments and $45 \mathrm{~S}$ rDNA signals on both sides, F. Late anaphase with seven $45 \mathrm{~S}$ signals in one of the poles. Scale bar: $5 \mu \mathrm{m}$.

Differences in the number and size of the $45 \mathrm{~S}$ signals were observed throughout mitosis (Figures 1-5). The largest, intact signals were on average $0.94 \mu \mathrm{m}$, the mean signals $0.48 \mu \mathrm{m}$, and the smallest signals were $0.2 \mu \mathrm{m}$. During prophase, metaphase, and anaphase gaps were evidenced in $45 \mathrm{~S}$ rDNA sites supporting the maintenance of the expression of FSs in the cell cycle in both Lolium species as well as in F. arundinacea (Figures 1, 2C-E, 3C-E, 4C-E and 5C-E).

Genetics and Molecular Research 16 (1): gmr16019156 

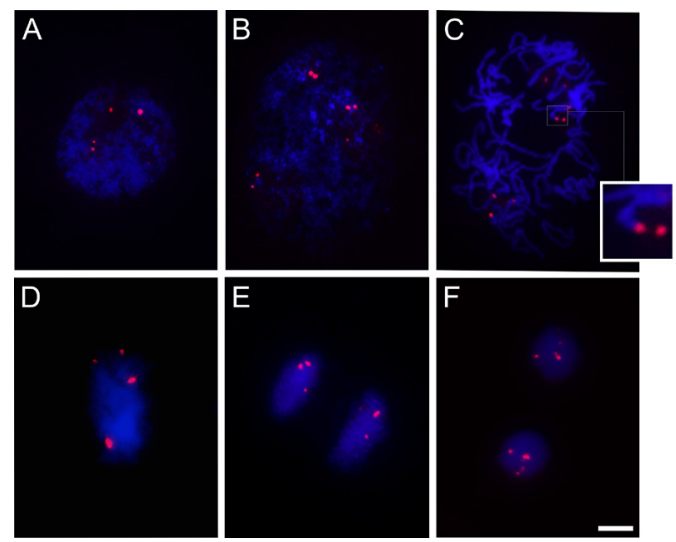

Figure 4. Cell cycle of Festuca arundinacea 'Rizomat' $(2 n=6 x=42)$, in red: 45 S rDNA signals, A. Interphase G1 with five $45 \mathrm{~S}$ rDNA signals, B. Interphase S/G2 with nine 45S rDNA signals, C. Prometaphase: the amplification shows a small chromosome segment co-located with a 45S signal, D. Metaphase with four 45S rDNA signals, E. Anaphase with three and four 45S rDNA signals, F. Telophase with four 45S rDNA signals. Scale bar: $5 \mu \mathrm{m}$.
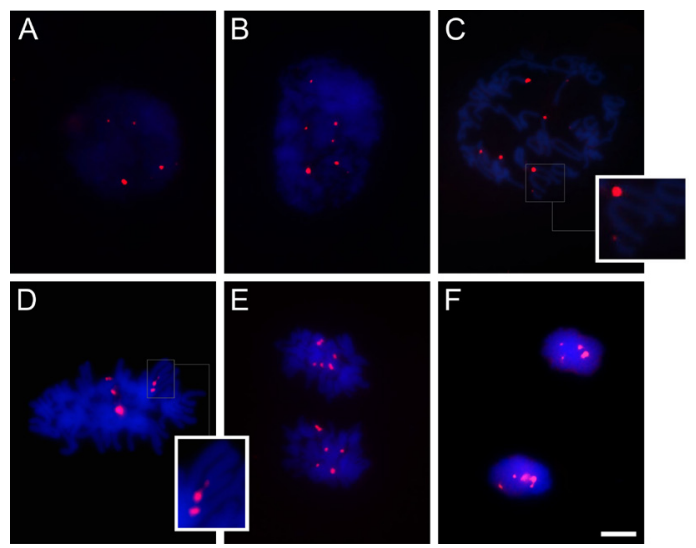

Figure 5. Cell cycle of Festuca arundinacea 'Quantum II' $(2 n=6 x=42)$, in red: 45S rDNA signals, A. Interphase $\mathrm{G} 1$ with four 45S rDNA signals, B. Interphase S/G2 with seven 45S rDNA signals, C. Prophase: the enlargement shows a chromosome with 45S rDNA signals of different sizes on both sides of the fragile chromosome, D. Metaphase: the enlargement shows a chromosome with a gap in the 45S rDNA site, E. Anaphase with six 45S signals on each pole, $\mathbf{F}$. Telophase with four and five $45 \mathrm{~S}$ rDNA signals. Scale bar: $5 \mu \mathrm{m}$.

Structurally, the chromosome appeared to be segmented and the 45S rDNA probe sometimes marked this region (Figures 2C and D, 3C-E, 4C and 5C). In the studied Lolium species, such segments corresponded to about $1 / 3$ of the chromosome size, due to interstitial $45 \mathrm{~S}$ sites with FSs (Figures 2C-E and $3 \mathrm{C}-\mathrm{E}$ ). In contrast, in F. arundinacea small chromosome segments always co-located with $45 \mathrm{~S}$ signals along its length due to $45 \mathrm{~S}$ sites being located in terminal positions (Figure 4C) and larger segments (Figure 5C and D).

Only at the early anaphases of $L$. perenne it was possible to observe one or two segments spaced from the chromatid of origin, which had already been segregated (Figure $3 \mathrm{E})$. Nevertheless, in all studied species, the late anaphases and telophases had close to the expected number of $45 \mathrm{~S}$ rDNA signals (Figures 1, 2E and F, 4F, and 5F). In L. perenne and $L$. 
multiflorum, the segmented part, whether followed by $45 \mathrm{~S}$ rDNA signals or not, was located only at the proximal region of the chromosome (Figures $2 \mathrm{E}$ and $3 \mathrm{~F}$ ).

\section{DISCUSSION}

In interphasic $\mathrm{G} 1$ nuclei, the number of $45 \mathrm{~S}$ signals measured was similar to the descriptions for mitotic chromosomes with six, seven, and four/five sites for L. multiflorum, $L$. perenne, and F. arundinacea, respectively (Thomas et al., 1996, 1997; Bustamante et al., 2014; Rocha et al., 2015). In S/G2 nuclei, the number of $45 \mathrm{~S}$ signals was higher for the three species studied here owing to the occurrence of FSs. This indicates that the fragility of sites, apparently splitting the 45S site into two, coincides with the DNA replication, as has been suggested for human chromosomes (Wang, 2006; Leman and Noguchi, 2013). It has been shown that one of the causes of the formation of FSs in humans is replicative stress that promotes a delay in the replication fork and/or colisions between the replication and transcription machinery that maintains the DNA strand unzipped, which might result in breakages of the double-stranded DNA (Wang, 2006; Leman and Noguchi, 2013).

Additional evidence suggesting that FSs are expressed during interphase was provided by Huang et al. (2009). In their study, the $45 \mathrm{~S}$ rDNA sites of $L$. perenne were highly decondensed in more than $90 \%$ of the G2 nuclei and the authors suggested that failure in the chromatin folding complex of these sites could be responsible for the spontaneous formation of FSs (Huang et al., 2009). In another study, following induction with actinomicin D (a transcription inhibitor) and aphidicolin (a replication inhibitor), the interphasic nuclei of maize, rice, barley, shorgum, and ryegrass were highly decondensed and had fiber-like thread after FISH 45S in metaphasic chromosomes (Huang et al., 2012). Thus, it is likely that the replicative and transcriptional processes are involved with the spontaneous FSs in Lolium and Festuca.

The chromosome fragility in $45 \mathrm{~S}$ rDNA sites in Lolium and Festuca detected by the high chromatin decondensation during the cell cycle is supported by a recent review by Dvoŕáčková et al. (2015). They suggest that the rDNA is a region prone to fragility or instability due to the high transcriptional activity that may take place throughout the cell cycle, including the S phase of interphase (Dvoŕáčková et al., 2015). The intense transcription may delay the replicative process, cause collision between these two machineries in the rDNA, and interfere with the cohesion between sister chromatids (Ide et al., 2010; Dvořáčková et al., 2015). As Huang et al. (2012), Bustamante et al. (2014), and Rocha et al. (2015) have already demonstrated, the $45 \mathrm{~S}$ fragile sites in Lolium species have high and variable transcriptional activity as evidenced by silver-staining nucleolar organizer regions (AgNOR).

One of the explanations for the stability of FSs in Lolium and Festuca is that as the cell cycle is a continuous process in which cells maintain the exceeding number of $45 \mathrm{~S}$ rDNA signals, as well as the decondensed status in this region up to anaphase (Figure 6) with no breakages. The replication of $45 \mathrm{~S}$ rDNA sites, so far delayed due to the collision with the transcription machinery, likely occurs during or even after segregation, as proposed by Chan et al. (2009). The end of the replication reaches its peak with the resumption of the condensation of FSs of Lolium and Festuca at a level similar to the other chromatid regions, restoring the number of $45 \mathrm{~S}$ signals in late anaphases, telophases, and favoring the approximation of chromosome segments (Figure 6). In this case, it is also possible that a minimum condensation status required to assure the segregation of the remaining parts of the fragile chromosomes is maintained, therefore, retaining genome stability. Such behavior may explain the stability

Genetics and Molecular Research 16 (1): gmr16019156 
of the DNA content found by means of flow cytometry in L. multiflorum, L. perenne, and F. arundinacea (Bustamante et al., 2015; Rocha et al., 2016) and the low percentage of micronuclei $(<1 \%)$ observed by Rocha et al. (2016) in the same species.

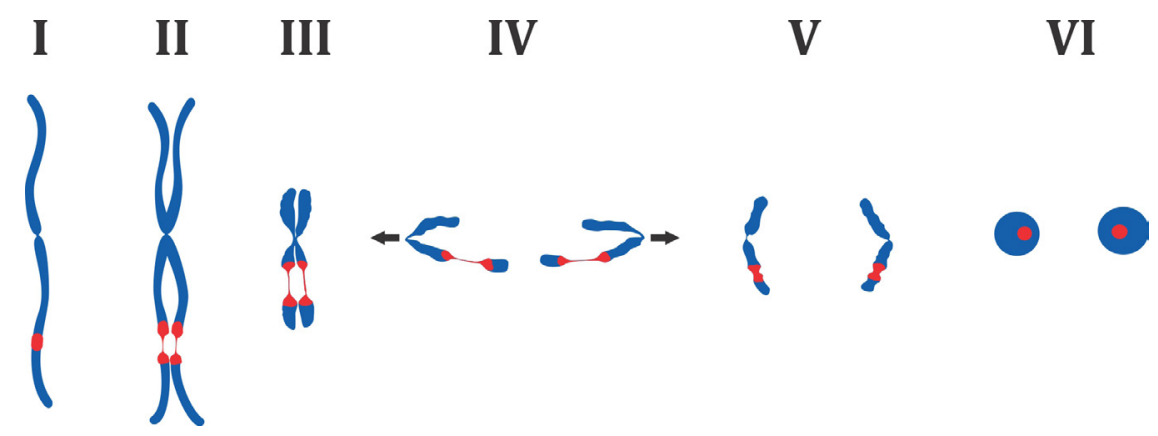

Figure 6. Schematic of the dynamic condensation in 45S rDNA signals during the cell cycle. I: Phase G1, II: Phase S/G2 with decondensation in 45S rDNA sites, III: Prophase/Metaphase chromosomes with decondensed 45S, even after the condensation of the remaining of the chromosome, IV and V: 45S rDNA signals in chromatids go back to a compaction level similar to the remaining of the DNA after segregating, VI: In telophase, 45S rDNA sites have the number of signals expected, with no leftover.

In FSs, the DNA fibers are generally not visible when contrasted with conventional staining, with DAPI, and sometimes with techniques such as FISH. The methods used to prepare slides and the pre-hybridization might break the fine DNA fibers, seeming to form chromosome fragments. Although the chromatin fibers were not evident in all FSs in the present study, they are responsible for the chromosome stability observed in the evaluated Lolium and Festuca species. In a previous study, Rocha et al. (2016) did not find evidence for the hypothesis that the neocentromere activity in presumable chromosome fragments would be responsible for the stability of the genome of Lolium, Festuca, and Festulolium hybrids.

The delay in the replication, as well as other possible damages in the chromatin, may be restored during the cell cycle as described by Chan et al. (2009). In their study, the authors reported the role played by replication factors (helicases) and DNA repairing (FANDC2) after the segregation of chromatids in human fibroblasts treated with a replication inhibitor (aphidicolin) that promotes the expression of FSs. In their study, they also found a co-location of FANDC2 marks, DNA repairing protein, along with 45S rDNA sites from prometaphase to late anaphase of fibroblasts, which suggests that the repairing mechanism and replication completion are active even during segregation (Chan et al., 2009). Interestingly, only 10\% of the FANDC2 marks seen in metaphases were present in anaphases. This suggests that FANDC2 is efficient in repairing the DNA structure during the early phases of cell division or even after the beginning of anaphase. Thus, the presence of repair during cell division could be a potential mechanism to maintain FSs, compensating for any failures of replication checkpoints in interphase, and concluding the replication in $45 \mathrm{~S}$ rDNA sites that had not been finished in interphase, which is one of the causes of the expression of fragility.

We observed that FSs occur regularly and non-induced during the cell cycle of $L$. perenne, L. multiflorum, and F. arundinacea. The method by which FSs are expressed does not promote any genome/chromosome instability, since there is no formation of fragments or loss of genetic material that might result in deleterious effects for the studied species.

Genetics and Molecular Research 16 (1): gmr16019156 
Studies on FSs conducted so far have described the spontaneous expression in C-metaphases of Lolium and Festuca (Huang et al., 2008; Bustamante et al., 2014; Rocha et al., 2015, 2016). In these studies, C-metaphases are in general obtained through a block with cold water for $24 \mathrm{~h}$. The suspicion that FSs could be due to the effect of heat shock was supported by Guarido et al. (2012), who demonstrated that some regions of plant chromosomes belonging to the genus Solanum are prone to undergo decondensation when exposed to low temperatures and these regions are denominated cold sensitive. Results obtained with analysis of the cell cycle in the present study confirmed that the expression of FSs is spontaneous and independent of the treatment of Lolium and Festuca. Signals of the 45S rDNA probe and the site of FS occurrence were observed in variable numbers and sizes in the three studied species. Furthermore, gaps were observed, which are typical of the occurrence of FSs.

Future epigenetic studies will allow for further examination of which events are involved in the high decondensation of 45S rDNA sites, an extremely important multigene family for the maintenance of the cell metabolism. Future studies will also allow us to understand the dynamics that promote fragility and allow gene stability, in addition to elucidating the feasible evolutionary and biological meaning of the peculiar behavior observed in 45S rDNA sites in Lolium and Festuca.

\section{Conflicts of interest}

The authors declare no conflict of interest.

\section{ACKNOWLEDGMENTS}

Authors are thankful to Conselho Nacional de Desenvolvimento Científico e Tecnológico (CNPq), Fundação de Amparo à Pesquisa do Estado de Minas Gerais (FAPEMIG), and Coordenação de Aperfeiçoamento de Pessoal de Nível Superior (CAPES) for the financial support to the research and the scholarship provided.

\section{REFERENCES}

Bustamante FO, Rocha LC, Torres GA, Davide LC, et al. (2014). Distribution of rDNA in diploid and polyploid Lolium multiflorum Lam. and fragile sites in 45S rDNA regions. Crop Sci. 54: 617-625. http://dx.doi.org/10.2135/ cropsci2013.05.0325

Bustamante FO, Rocha LC, Santos NS, Silveira RAD, et al. (2015). Analysis of nuclear DNA content and chromosome number for screening genotypes and crosses in Annual Ryegrass (Lolium multiflorum Lam.). Aust. J. Crop. Sci. 9: 666-670.

Chan KL, Palmai-Pallag T, Ying S and Hickson ID (2009). Replication stress induces sister-chromatid bridging at fragile site loci in mitosis. Nat. Cell Biol. 11: 753-760. http://dx.doi.org/10.1038/ncb1882

Dong F, Song J, Naess SK, Helgeson JP, et al. (2000). Development and applications of a set of chromosome-specific cytogenetic DNA markers in potato. Theor. Appl. Genet. 101: 1001-1007. http://dx.doi.org/10.1007/s001220051573

Dvořáčková M, Fojtová M and Fajkus J (2015). Chromatin dynamics of plant telomeres and ribosomal genes. Plant J. 83: 18-37. http://dx.doi.org/10.1111/tpj.12822

Glover TW (2006). Common fragile sites. Cancer Lett. 232: 4-12. http://dx.doi.org/10.1016/j.canlet.2005.08.032

Grabowska-Joachimiak A, Kula A, Gernand-Kliefoth D and Joachimiak AJ (2015). Karyotype structure and chromosome fragility in the grass Phleum echinatum Host. Protoplasma 252: 301-306. http://dx.doi.org/10.1007/s00709-014-0681-5

Guarido PC, de Paula AA, da Silva CRM, Rodriguez C, et al. (2012). Hypomethylation of cytosine residues in coldsensitive regions of Cestrum strigilatum (Solanaceae). Genet. Mol. Biol. 35: 455-459. http://dx.doi.org/10.1590/ $\underline{\text { S1415-47572012005000026 }}$

Genetics and Molecular Research 16 (1): gmr16019156 
Huang J, Ma L, Yang F, Fei SZ, et al. (2008). 45S rDNA regions are chromosome fragile sites expressed as gaps in vitro on metaphase chromosomes of root-tip meristematic cells in Lolium spp. PLoS One 3: e2167. http://dx.doi.org/10.1371/ journal.pone.0002167

Huang J, Ma L, Sundararajan S, Fei SZ, et al. (2009). Visualization by atomic force microscopy and FISH of the 45S rDNA gaps in mitotic chromosomes of Lolium perenne. Protoplasma 236: 59-65. http://dx.doi.org/10.1007/s00709$\underline{009-0051-\mathrm{X}}$

Huang M, Li H, Zhang L, Gao F, et al. (2012). Plant 45S rDNA clusters are fragile sites and their instability is associated with epigenetic alterations. PLoS One 7: e35139. http://dx.doi.org/10.1371/journal.pone.0035139

Ide S, Miyazaki T, Maki H and Kobayashi T (2010). Abundance of ribosomal RNA gene copies maintains genome integrity. Science 327: 693-696. http://dx.doi.org/10.1126/science.1179044

Lan H, Chen C, Miao Y, Yu C, et al. (2016). Fragile sites of 'Valencia' sweet orange (Citrus sinensis) chromosomes are related with active 45s rDNA. PLoS One 11.3: e0151512

Leman AR and Noguchi E (2013). The replication fork: understanding the eukaryotic replication machinery and the challenges to genome duplication. Genes (Basel) 4: 1-32. http://dx.doi.org/10.3390/genes4010001

Pereira RC, Ferreira MTM, Davide LC, Pasqual M, et al. (2014). Chromosome duplication in Lolium multiflorum Lam. Crop Breed. Appl. Biotechnol. 14: 251-255. http://dx.doi.org/10.1590/1984-70332014v14n4n39

Richards RI (2001). Fragile and unstable chromosomes in cancer: causes and consequences. Trends Genet. 17: $339-345$. http://dx.doi.org/10.1016/S0168-9525(01)02303-4

Rocha LC, Bustamante FdeO, Silveira RA, Torres GA, et al. (2015). Functional repetitive sequences and fragile sites in chromosomes of Lolium perenne L. Protoplasma 252: 451-460. http://dx.doi.org/10.1007/s00709-014-0690-4

Rocha LC, Jankowska M, Fuchs J, Mittelmann A, et al. (2016). Decondensation of chromosomal 45S rDNA sites in Lolium species and Festuca genotypes does not result in karyotype instability. Protoplasma http://dx.doi.org/10.1007/ s00709-016-0942-6.

Thomas HM, Harper JA, Meredith MR, Morgan WG, et al. (1996). Comparison of ribosomal DNA sites in Lolium species by fluorescence in situ hybridization. Chromosome Res. 4: 486-490. http://dx.doi.org/10.1007/BF02261775

Thomas HM, Harper JA, Meredith MR, Morgan WG, et al. (1997). Physical mapping of ribosomal DNA sites in Festuca arundinacea and related species by in situ hybridization. Genome 40: 406-410. http://dx.doi.org/10.1139/g97-054

Waminal NE, Ryu KH, Choi SH and Kim HH (2013). Randomly detected genetically modified (GM) maize (Zea mays L.) near a transport route revealed a fragile 45S rDNA phenotype. PLoS One 8: e74060. http://dx.doi.org/10.1371/ journal.pone.0074060

Wang YH (2006). Chromatin structure of human chromosomal fragile sites. Cancer Lett. 232: 70-78. http://dx.doi. org/10.1016/j.canlet.2005.07.040

Genetics and Molecular Research 16 (1): gmr16019156 